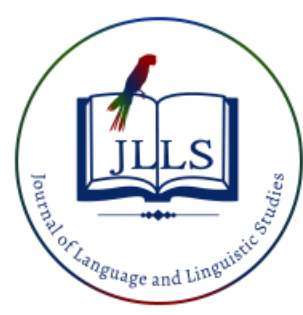

Available online at www.jlls.org

JOURNAL OF LANGUAGE AND LINGUISTIC STUDIES

ISSN: $1305-578 \mathrm{X}$

Journal of Language and Linguistic Studies, 17(1), 377-397; 2021

\title{
Comparing the melodies of Turkish and English speech: A focus on
}

\section{suprasegmentals}

\author{
Nur Sürüç Şen a ${ }^{\text {ID }}$ \\ ${ }^{a}$ Anadolu University, Turkey
}

\section{APA Citation:}

Sürüç Şen, N. (2021). Comparing the melodies of Turkish and English speech: A focus on suprasegmentals. Journal of Language and Linguistic Studies, 17(1), 377-397. Doi: 10.52462/jlls.23

Submission Date: 07/01/2021

Acceptance Date: 16/03/2021

\begin{abstract}
When it comes to paying attention to the suprasegmental features of their speech, most learners of English seem to be unaware that such phenomena as stress, pitch, duration, and pausing can be of great importance regarding mutual intelligibility. Since they carry a considerable weight of establishing an intelligible conversation, it is argued that they should take part in learners' curricula. In this light, the present study is set out to examine the suprasegmental features of a non-native learner and a native speaker, deriving similarities and diversions with regards to the way they operate the suprasegmental features in their speech data. Therefore, the present study analyses and compares some suprasegmental features of the speech data gathered from a Turkish learner of English and a native speaker of American English. In this vein, fifty sentences are read aloud separately by the Turkish learner of English and the native speaker. The similarities and diversion points are presented and analyzed to highlight some recursivities within the dataset. In this way, teachers and learners of English might be informed upon certain points to improve their intelligibility.
\end{abstract}

Keywords: suprasegmental features, non-native pronunciation, intelligibility, stress, intonation, pause

\section{Introduction}

The learners of English across the globe tend to practice English as a lingua franca (i.e.; ELF) as a vehicle for intelligible communication (Reed \& Michaud, 2011). In this vein, being able to transfer propositions that are comprehensible enough diverts from the idea of having a pronunciation level that is as close as possible to the native speakers of the target language. That is, two different approaches to pronunciation teaching have influenced the course of education in EFL contexts (Levis, 2005); the first one focusing on being functional and intelligible acknowledging the phenomenon labeled as World Englishes, the other one focusing on developing a pronunciation level that is more native-like as possible. Considering the paradigm related to intelligibility, teaching and learning pronunciation have gained some perspectives that give an opportunity to the non-native EFL learners to improve their comprehension of a spoken language and their pronunciation so that there would be mutual

\footnotetext{
1 Corresponding author.

E-mail address: nssuruc@anadolu.edu.tr
} 
intelligibility among speakers (Djebbari, 2014). Along with the instruction of segmental features covering the properties of consonants and vowels of the target language; suprasegmentals, which make up the functional melodies of languages, play a crucial role in establishing a meaningful interaction with the least amount of communication breakdowns (Celce-Murcia, Brinton, \& Goodwin, 2010). For instance, if learners come across with such a sentence uttered as "GOT the keys" with rising intonation, they should interpret this utterance as a question rather than a description of an action. Without the necessary information of suprasegmental units (stress, intonation, rhythm) regarding the English language, the learners might misunderstand the sequence of ongoing interaction and it might result in a communication breakdown.

The connection between intercommunication and suprasegmental features demonstrates that explicit pronunciation teaching with a special highlight of the features belonging to intonation, stress, and rhythm can benefit learners' ability to notice different functions above segmental features. In this regard, the area labeled as an outer circle (see Deterding, 1994; Sirsa \& Redford, 2013; Hussain \& Sajid, 2015) has been of interest in the previous literature in the past years. The outer circle here refers to an element belonging to Kachru's (1992) classification of World Englishes and covers the countries in mostly Asia and Africa, in which the spread of English as lingua franca is a product of imperial expansion. In this light, the expanding circle refers to those countries, which make use of English as international communication, without historical or governmental strings attached to it. Such contexts belonging to expanding circles (see Coates, 2020; Devitska, 2019; Diaz, 2017; O'neal, 2010) have been viewed as fertile fields of research mostly in the recent past. The studies mostly applied experimental paradigms investigating the evidence of overt pronunciation teaching of segmental and suprasegmental features towards an intercommunication with less inconvenience. These studies concluded that Turkish EFL learners bear difficulties in comprehending and/or producing English pronunciation in both segmental and suprasegmental features of speech sounds.

Utilized by native speakers without being aware of it, suprasegmentals set up a contextual ground that shapes meaning (Celce-Murcia, Brinton \& Goodwin, 2010). The violations of suprasegmental features, on the other hand, may damage the communication, implying that some violations are even considered impermissible by the native speakers (Yurtbaş1, 2017). Although there seems to be a considerable amount of interest in the segmental features of spoken language, suprasegmental features are taken as substantial (Florez, 1998) in that they have the potential to give clues about context or to make a change in meaning. Taking learners' point of view, those nuances can be even harder to perceive, since they might infer from the already existing suprasegmental properties of their native language. In this vein, attaining a sufficient amount of intelligibility might be demanding for nonnative EFL learners, especially considering the different nature of languages. As a syllable-timed language (Çelik, 2007; Bayraktaroğlu, 2008), Turkish contrasts with a stress-timed language such as English (Harmer, 2001). That is why; Turkish EFL learners have a tendency to generate sentences without regarding correct suprasegmental features of the English language unless they are made aware of such prosodic properties (Evis \& K1lıç, 2020). Training learners on such features might benefit from boosting their confidence, elaborating on their social experiences by making use of this invaluable interpretation tool, and improving the interlocutors' soundness overall (Morley, 1991).

\subsection{Literature review}

Interpreted by Goodwin (2013), pronunciation is regarded as the accuracy gained in segmental and suprasegmental features in speech (Ma, 2015). While segmental phonemes can be divided into smaller segments such as vowels and consonants; suprasegmental features equip segmental phonemes with different aspects that might change meaning in the forms including intonation, stress, and rhythm. By 
putting importance on the articulations of segmental features, learners of the target language might notice the array of phonemes in the language and compare them with their existing segmental feature knowledge that they carry in their mental warehouse. Identified as the key elements of pronunciation by Avery and Ehrlich (1992), suprasegmental features form the aspects of speech associated with more than one consonant or vowel; overall having the potential of modifying the meaning of the utterances.

Suprasegmental features involve aspects of speech such as stress, intonation, and rhythm. Stress is identified as the marked element in a word or sentence, accomplished by changing the pitch of the voice to longer, louder, or higher end. Depending on their properties as strong, weak, or unstressed; they carry importance in the intelligibility since a variety of stress might easily change the direction of the communication, causing breakdowns (Scribd, 2012).

In English, sentential stress patterns are regarded as tonic, emphatic, and contrastive stress (Çelik, 1999). Tonic stress is operated with function words such as pronouns, prepositions, and conjunctions, which are unstressed mostly (Celce-Murcia, et al, 2010; Çelik, 1999). On the other hand, emphatic stress is delivered in cases where further verification is required such as the use of pronouns like "yourself" or adverbs like "indeed" (Çelik, 2007; Arslan, 2013). As for contrastive stress, it is operated when a violation of tonic stress occurs; that is, a function word gets stressed. When it comes to word stress, it is argued that the first syllable of the word's base is usually stressed in the words with a Germanic origin such as "WAter" (Celce-Murcia, Brinton, \& Goodwin, 1996); whereas the stress on compound words is much more irregular. In this vein, verbs typically have the primary stress on the second syllable such as "preSENT", although some suffixation might change the placement of primary stress as in "EDUCAtion" or "deMOCracy" (Arslan, 2013).

In Turkish, if the predicate contains a verb phrase, the stress usually falls into the word or phrase right before the verb. However, if the verb is placed at the beginning of a sentence, the stress falls directly on it. On the other hand, the primary stress is on the predicate nominative in the cases where the predicate is a subject complement, regardless of the word order in the sentence. As for the word stress, it is typical that the stress falls on the final syllable of a word in Turkish. As there are exceptions, Lewis (1967) argues that most special place names have initial word stress. Other exceptions can be listed as the following rules (Göksel \& Kerslake, 2005, p. 26-28):

- Most adverbs are stressed on the first syllable.

- Most borrowed words are not stressed on the final syllable.

- Most place names are not stressed on the final syllable.

- Most question words are stressed on the first syllable.

- Some prefixes such as reduplication might divert the stress to the first syllable.

- There are irregularities with compound words.

Intonation, on the other hand, has several functions such as indexing a certain attitude of the speaker, indicating the type of the sentences or highlighting an element of importance in the utterance. The types of intonation include rising, falling, dipping, and peaking; depending on the movement of the pitch. These might signal completeness, uncertainty, approval, surprise, and so on, depending on the contextual use. Another element belonging to suprasegmental features is rhythm, which can be traced into the stress and pace patterns of syllables, words, phrases, and sentences towards shaping the overall intonation of the speech. In this respect, O'Connor (1973) argues that identifying languages as syllable-timed and stress-timed rhythm is crucial while unearthing prosodic features. Whereas syllable-timed rhythm belongs to those languages with the articulation of syllables, which are assigned with almost equal intervals of time; stress-timed rhythm belongs to those languages with stressed 
syllables are uttered at almost consistent intervals of time. Such stressed syllables are perceived louder, longer, and higher with respect to the pitch of a sound, while unstressed syllables are perceived as quieter, shorter, and lower, especially compared to stressed syllables.

In English, falling intonation is regarded as the most common type used for either providing or requesting certain information. It can be observed in statements, some question types, imperatives, exclamations, etc. On the other hand, rising intonation can index an argument that is not finalized, or certain emotions such as surprise, doubt, and interest. It can be exemplified in a particular type of questions, non-finite clauses, listing, addressing, etc.

In Turkish, falling intonation functions as an instrument of informing the listener that the utterance is getting finalized; whereas level intonation operates as notifying the listener that the argument being delivered is not finalized yet. On the other hand, fall-rise intonation delineates an expectation for an answer since it is usually operated with questions (Ergenç, 1989).

The highlight of suprasegmental features in pronunciation education has been regarded as fruitful since explicit instruction can make difference in the spontaneous production of the learners, compared to instruction with only segmental features covering vowels and consonants (Derwing, Munro, \& Wiebe, 1998). In fact, previous literature has demonstrated that such elaboration might boost intelligibility in communication and prevent disappointment caused by misunderstanding (CelceMurcia, et al., 1996). On the other hand, there seems to be a dominance of segmental features in most pedagogical curricula belonging to foreign or second language contexts (Chela-Flores, 2003).

\subsection{Research questions}

Set out by such weight of suprasegmental features in developing learners' intelligibility, the present study aims to depict the use of the suprasegmental features (i.e., stress, intonation, rhythm) by American and Turkish speakers upon their readings of fifty English sentences. Therefore, the present study focuses on the research questions as delineated hereunder:

RQ1-How is the length of syllables assigned across native and non-native spoken data?

RQ2-How is the stress of syllables assigned across native and non-native spoken data?

RQ3-How is the pitch of syllables assigned across native and non-native spoken data?

RQ4-How is pausing assigned across native and non-native spoken data?

In this way, the analysis of two sets of suprasegmental features might give rise to a more meaningful direction towards obtaining an intelligible pronunciation. This descriptive analysis of such utilization might inform the readers in the following ways:

- It might inform Turkish learners of English upon their utilization of suprasegmental features.

- The findings might spark EFL teachers' interest in teaching suprasegmental features so that the learners could improve their intelligibility.

- The learners might be informed about the factors affecting the quality of communication beyond phonemes.

- Noticing activities derived from the findings of the present study might be given a room in course books and teacher aid materials.

- Diversity between the language systems might give rise to linguistic and cultural awareness considering the target language. 


\section{Method}

\subsection{Sample and Data Collection}

The present study aims to analyze the aspects of speech such as stress, intonation, and rhythm through examining the loudness, pitch forms, duration, and pausing of two sets of spoken data delivered by a native (henceforth, Simon) and a non-native speaker (henceforth, Arda). By examining the suprasegmental patterns found in their speech, the analysis aims to unveil the problematic areas for pronunciation, considering Turkish learners of English. In this regard, ALLSTAR Corpus (See Bradlow (n.d) and Smiljanic \& Bradlow (2005) for more information), which is an online archive of speech recordings of several languages, is utilized in the current study. With an online request made on their official website, the speech recording data of a male native speaker of American English (i.e., Simon) is sent to the researcher via the SpeechBox interface. Having granted the consent for using recorded speech data for this study, fifty recordings of Simon have been selected for the suprasegmental analysis. The recordings are transcribed and listed in Appendix A.

Arda is a 26-year-old Turkish learner of English with sixteen years of experience in learning it as a foreign language. He reports himself as having a level of upper-intermediate in English. He does not use English in daily activities but rather enjoys the global culture brought alongside socializing online in English. Arda studies English so that he could assure a substantially significant score in a high-stake examination, which is used as an incentive for promotion in the company he works. Constituting as the focused participant, Arda read the utterances from the aforementioned list, and the process is also audio recorded so that the speech recording can be unfolded for the analysis. The readings of Simon are analyzed in the same way, to ensure a comparison for the spoken data delivered by Arda.

\subsection{Data analysis}

During the analysis, the application software of PRAAT is used to identify the duration and the loudness of the syllables, contours of tone, and pauses utilized in the spoken data. PRAAT operates as a platform, in which speech analysis can be conducted through checking elements such as pitch, intensity, and formant variants. In this respect, the procedure of the analysis is provided hereunder, step by step:

i. Length of each syllable is extracted by selecting each syllable and writing the duration of the speech in milliseconds.

ii. Hertz of each syllable is found by using the feature Pitch $>$ Get Pitch.

iii. The longest and the loudest syllables are found and highlighted.

iv. The loudest syllable is measured and compared to the whole utterance in percentage.

v. The intensity contour is measured using the feature Intensity $>$ Draw visible intensity contour.

vi. The pauses among the utterances are extracted manually and measured in milliseconds

\section{Results}

\subsection{Length assignment}

To analyze which syllable the speakers spent the longest time in uttering, time intervals are found and compared the use of length between the spoken data belonging to Arda and Simon. Table 1 demonstrates the listed utterances of the similarities and differences found in their speech. 
Table 1. Length variation across participants

\begin{tabular}{|c|c|}
\hline Same Length & $\begin{array}{l}\text { Different Length (Arda, Simon) } \\
\end{array}$ \\
\hline He lost his white hat today. & Twins live with their grandparents. \\
\hline The party game was really easy. & Leaves change color in the fall. \\
\hline Blueberry pie baked in the oven. & Finding a job is difficult in the present economic climate. \\
\hline Couples entertain around the holidays. & $\begin{array}{l}\text { The local train left the train station, more than five } \\
\text { minutes ago. }\end{array}$ \\
\hline The show ended early today. & $\begin{array}{l}\text { The committee will meet this afternoon for a special } \\
\text { debate. }\end{array}$ \\
\hline The artist studies Italian and French. & $\begin{array}{l}\text { Science has acquired an important place in western } \\
\text { society. }\end{array}$ \\
\hline Artists have always been attracted by life in the capital. & $\begin{array}{l}\text { Much more money will be needed to make this project } \\
\text { succeed. }\end{array}$ \\
\hline The art gallery in this street was open only last week. & This supermarket had to close due to economic problems. \\
\hline A hurricane was announced this afternoon on the TV. & $\begin{array}{l}\text { In this case, the easiest solution seems to appeal to the } \\
\text { high court. }\end{array}$ \\
\hline This rugby season promises to be a very exciting one. & The next local elections will take place during the winter. \\
\hline $\begin{array}{l}\text { Nobody noticed when the children slipped away just after } \\
\text { dinner. }\end{array}$ & $\begin{array}{l}\text { Parents quietly crossed the darkroom and approached the } \\
\text { boy's bed. }\end{array}$ \\
\hline $\begin{array}{l}\text { In this famous coffee shop, you will eat the best donuts in } \\
\text { town. }\end{array}$ & $\begin{array}{l}\text { The first flowers have bloomed through the exceptional } \\
\text { warmth of March. }\end{array}$ \\
\hline $\begin{array}{l}\text { The young boy got up quite early in order to watch the } \\
\text { sunrise. }\end{array}$ & The library is opened every day from 8 am to $6 \mathrm{pm}$. \\
\hline $\begin{array}{l}\text { The last concert given in the Opera was a tremendous } \\
\text { success. }\end{array}$ & $\begin{array}{l}\text { My grandparents' neighbor is the most charming person I } \\
\text { know. }\end{array}$ \\
\hline Car's going too fast. & Her shoes were very dirty. \\
\hline A letter fell on the floor. & Mother tied the string too tight. \\
\hline Sugar is very sweet. & The kitchen sink is empty. \\
\hline There was a bad train wreck. & The house had nine bedrooms. \\
\hline They had some cold cuts for lunch. & They called an ambulance. \\
\hline The sun melted the snow. & Poached eggs and tea must suffice. \\
\hline Scissors are very sharp. & Post no bills on this office wall. \\
\hline The man is painting a sign. & The marsh will freeze when cold enough. \\
\hline \multicolumn{2}{|l|}{ The kitchen window is clean. } \\
\hline \multicolumn{2}{|l|}{ The mailman brought a letter. } \\
\hline \multicolumn{2}{|l|}{ The girl caught a head cold. } \\
\hline \multicolumn{2}{|l|}{ The candy shop is empty. } \\
\hline \multicolumn{2}{|l|}{ A white silk jacket goes with any shoe. } \\
\hline A list of names is carved around the base. & \\
\hline
\end{tabular}

As seen in Table 1 above, out of 50 sentences, 28 sentences have found to be similar in Arda and Simon's speech in terms of the syllable they assign the longest time of utterance. 17 out of 28 instances, the speakers both uttered the last syllable the longest, in line with the expectation. On the other hand, 7 of them belong to the subject or part of the subject, as displayed in Table 2 with the instance. The subject is an open syllable starting with a fricative, which might have an effect on spending longer time to utter compared to the rest of the sentence.

Table 2. Similar length instance (subject)

\begin{tabular}{|l|l|l|l|l|l|l|l|}
\hline Syllable & Show & end & ed & ear & ly & to & day \\
\hline Length (Simon) & $\mathbf{3 2 3}$ & 201 & 156 & 131 & 183 & 125 & 227 \\
\hline Length (Arda) & $\mathbf{4 3 6}$ & 229 & 142 & 164 & 153 & 125 & 309 \\
\hline
\end{tabular}


In a similar vein, 4 of them belong to the verb or part of the verb, as it can be examined in the following instance (see Table 3), in which the longest syllable is found to be the same for each speaker, although it must be taken into consideration that the syllable "promis" has more segments than the rest of the syllables in the utterance.

Table 3. Similar length instance (verb)

\begin{tabular}{|l|l|l|l|l|l|l|l|l|l|l|l|l|l|l|l|}
\hline Syllable & This & rug & by & sea & son & promis & es & to & be & a & very & ex & ci & ting & one \\
\hline $\begin{array}{l}\text { Length } \\
\text { (Simon) }\end{array}$ & 258 & 339 & 222 & 301 & 182 & $\mathbf{4 6 0}$ & 248 & 156 & 165 & 102 & 436 & 271 & 156 & 169 & 291 \\
\hline $\begin{array}{l}\text { Length } \\
\text { (Arda) }\end{array}$ & 139 & 225 & 162 & 274 & 258 & $\mathbf{3 8 4}$ & 172 & 083 & 089 & 094 & 301 & 175 & 180 & 200 & 254 \\
\hline
\end{tabular}

With respect to the diversion points of length, 22 utterances out of 50 seem to be relevant under this category. 7 of the instances demonstrate that Arda seems to follow the common pattern and assign the longest duration of utterance to the last syllable; whereas Simon assigns the longest duration to some other syllables (See Table 4). As can be seen in the instance, Arda assigns the longest duration to the first syllable, "twins" and it can be observed that he adds a vowel to break up the consonant cluster at the beginning, which shows traces of the Turkish phonology rule that does not allow a consonant cluster at the beginning of a word and that insertion of a vowel is commonly utilized to utter such words. This might be one of the possible explanations to account for the considerable time spent in articulating the syllable "twins".

Table 4. Diversion in length assignment

\begin{tabular}{|l|l|l|l|l|l|l|l|}
\hline Syllable & Twins & live & with & their & grand & pa & rents \\
\hline Length (Simon) & 303 & 171 & 153 & 149 & 231 & 149 & $\mathbf{3 4 2}$ \\
\hline Length (Arda) & $\mathbf{7 7 1}$ & 533 & 261 & 306 & 323 & 181 & 669 \\
\hline
\end{tabular}

In addition, it can be observed that 4 of the utterances bear such conditions on the other way around. That is, Simon seems to be putting the longest duration to the last syllable as he commonly does as a native speaker; but Arda seems to have assigned the longest duration to other syllables (See Table 5). The syllable "tight" is uttered with a lengthening of the vowel and a clear "t" sound at the end by Arda. Meanwhile, Simon pronounces it with a shorter duration as in "tart" but it sounds almost like a glottal sound (?) at the end, shortening the duration of the syllable even further.

Table 5. Diversion in length assignment

\begin{tabular}{|l|l|l|l|l|l|l|l|}
\hline Syllable & Mo & ther & tied & the & string & too & tight \\
\hline Length (Simon) & 130 & 120 & 166 & 108 & $\mathbf{3 3 6}$ & 150 & 230 \\
\hline Length (Arda) & 238 & 131 & 226 & 109 & 455 & 229 & $\mathbf{5 2 3}$ \\
\hline
\end{tabular}




\subsection{Stress assignment}

The use of stress in utterances has been identified through measuring the loudness of each syllable in Hertz (See Appendix B and C for the detailed list). Additionally, the proportion of the stressed syllable's duration compared to the whole utterance's duration is measured in percentages so that the stress assignment of Simon and Arda could be compared in percentages.

The analyses of loudness demonstrate that Simon and Arda have assigned the stress on the same syllable in 13 instances out of 50. They seem to have put the stress on the subject $(n=8)$, verb $(n=3)$, an adverb $(n=2)$. As can be seen in Table 6 , some cases contain more segments than unstressed syllables, such as "floor" and "kitchen", therefore it might not be valid to compare them with other syllables. On the other hand, as a non-native EFL learner, Arda seems to be on the same page with Simon in terms of stress assignment with the utterances delineated in Table 6 below.

Table 6. Stress assignment (similarity)

\begin{tabular}{|c|l|}
\hline $\begin{array}{c}\text { No. } \\
\text { Utterance }\end{array}$ & Similarity in Stress Assignment \\
\hline U4 & Blueberry pie baked in the oven. \\
\hline U5 & Couples entertain around the holidays. \\
\hline U8 & Leaves change color in the fall. \\
\hline U19 & This supermarket had to close due to economic problems. \\
\hline U20 & In this famous coffee shop, you will eat the best donuts in town. \\
\hline U29 & Her shoes were very dirty. \\
\hline U30 & Car's going too fast. \\
\hline U31 & A letter fell on the floor. \\
\hline U33 & Sugar is very sweet. \\
\hline U37 & The kitchen sink is empty. \\
\hline U41 & The kitchen window is clean. \\
\hline U42 & The mailman brought a letter. \\
\hline U43 & They called an ambulance. \\
\hline U48 & Post no bills on this office wall. \\
\hline
\end{tabular}

When it comes to the stress proportions of the stressed utterances as compared to the whole utterances, Figure 1 paves the way for a better understanding of how stressed words are located and proportioned in those sentences in terms of loudness. As can be inferred, Simon seems to have situated the stressed syllables in much higher percentages than Arda, in terms of duration of the stressed syllables. That is, there is a higher proportion of stressed syllables in Simon's utterances (displayed in Figure 1) considering the time spent in uttering the whole sentence. This might indicate that Arda might be using stress less significantly in terms of the proportion of the stressed syllables' duration; thus, assigning more time to other syllables than the stressed ones, as compared to Simon in this sense. 


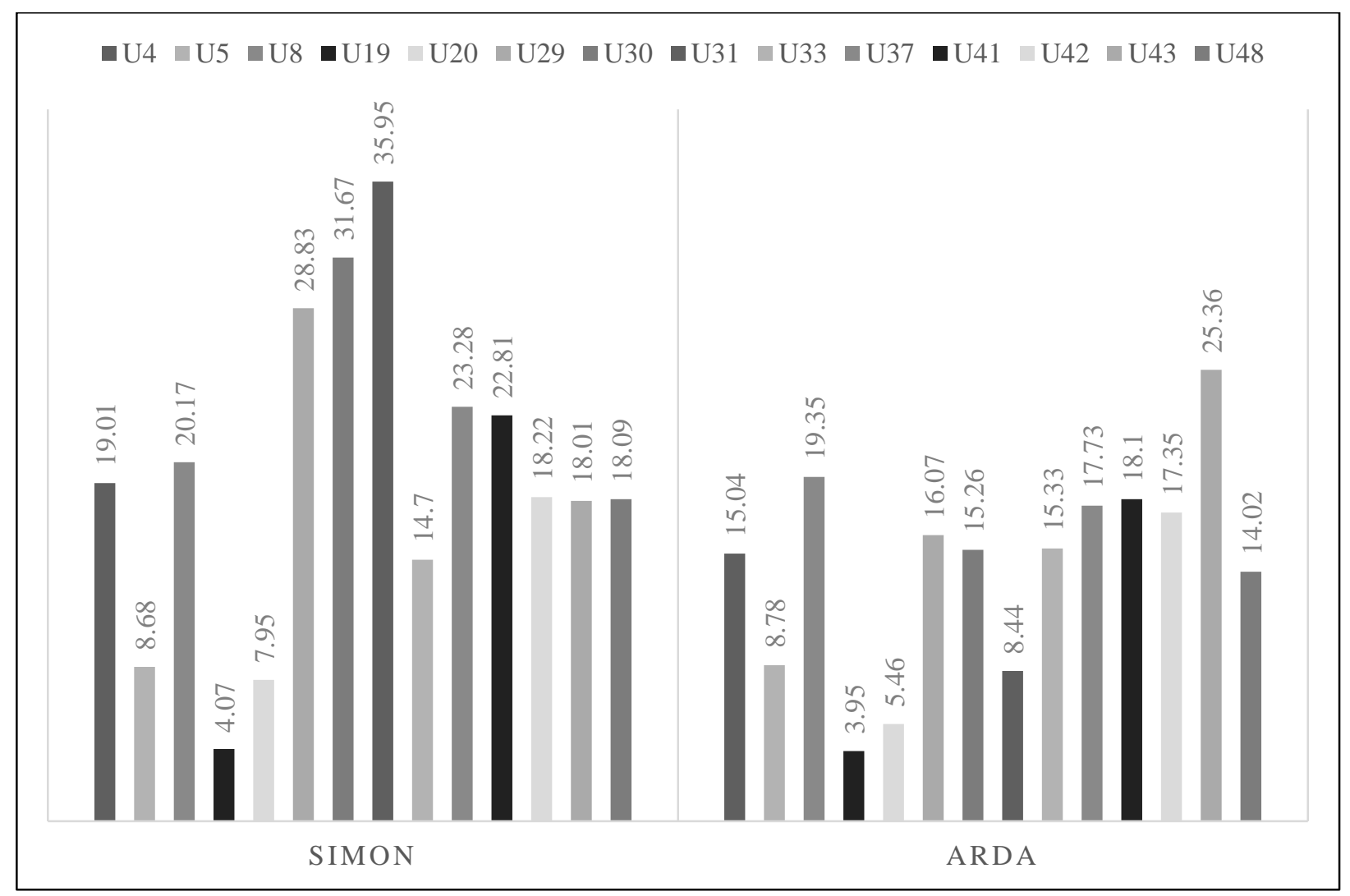

Figure 1. Stressed syllable percentage (similarity)

When it comes to the diversions that occurred in the stress patterns, a majority of the instances $(n=37)$ are found to be belonging to such category in the data set. Looking closer to the instances where Simon and Arda have a difference in assigning stress to the syllables, Figure 2 displays the cases, in which Arda chooses the subjects or a part of the subjects for assigning the stress whereas Simon assigns the stress to VP, AdvP, PP, O, and AdjP as shown below. The instances where Simon stresses the VP seem to be including subject, verb, object, and prepositional phrases. In such instances, unlike Arda, the action seems to be stressed rather than subject by Simon. However, the addition of an adverbial phrase might increase the alternative syllables to be stressed by Simon as observed in Figure 2, especially in passive sentences. Meanwhile, Arda continues to assign stress to the subject even in passive sentences, which might result in a glitch in communication since subjects seem to be left behind the actions in passive sentences. Similarly, objects are highlighted in the utterances 17 and 35, in which Arda puts the stress on the subjects. 


\begin{tabular}{|c|c|c|}
\hline \multirow{12}{*}{$\begin{array}{l}\text { *Subjects } \\
\text { or parts of } \\
\text { the } \\
\text { subjects } \\
\text { are } \\
\text { stressed by } \\
\text { Arda in all } \\
\text { of the } \\
\text { utterences } \\
\text { displayed } \\
\text { here. }\end{array}$} & \multirow[t]{4}{*}{ Verb Phrase } & 39-The house had nine bedrooms. \\
\hline & & 40-The man is painting a sign. \\
\hline & & 44-The girl caught a head cold. \\
\hline & & 50-A list of names is carved around the base. \\
\hline & \multirow[t]{3}{*}{ Adverbial Phrase } & 13-A hurricane was announced this afternoon on the TV. \\
\hline & & 23-Parents quietly crossed the dark room and approached the boy's bed. \\
\hline & & $27-$ The library is opened every day from 8 am to $6 \mathrm{pm}$. \\
\hline & \multirow[t]{2}{*}{ Prepositional Phrase } & 3-Twins live with their grandparents. \\
\hline & & 14-The committee will meet this afternoon for a special debate. \\
\hline & \multirow{3}{*}{ Object } & 17-Science has acquired an important place in western society. \\
\hline & & \\
\hline & & 35-They had some cold cuts for lunch. \\
\hline
\end{tabular}

Figure 2. Diversion in stress assignment (Arda-subject)

In the cases where the subject seems to be stressed by Simon, Arda assigns the stress on verb phrases (See Figure 3). When compared to Figure 2, it can be inferred that Simon assigns the stress on the verb phrases rather than subjects in the cases where the subject is usually formed with determiners, although there are exceptions in the utterances 7 and 36. Similar to Figure 1, Simon assigns the stress in the adverbial phrases but Arda chooses the verb phrases for the stressed syllables. In this vein, utterance 1 is an example, in which Simon underlines the object, where Arda is interested in stressing the subject. It can be implied from Figures 2 and 3 that Arda has a narrower span for stress assignment as compared to that of Simon.

\begin{tabular}{|c|c|c|}
\hline \multirow{10}{*}{$\begin{array}{l}\text { *Verbs or } \\
\text { parts of } \\
\text { the verbs } \\
\text { are } \\
\text { stressed } \\
\text { by Arda in } \\
\text { all of the } \\
\text { utterences } \\
\text { displayed } \\
\text { here. }\end{array}$} & \multirow[t]{6}{*}{ Subject } & 6-Show ended early today. \\
\hline & & 7-The artist studies Italian and French. \\
\hline & & 11-Artists have always been attracted by the life in the capital. \\
\hline & & 16-Nobody noticed when the children slipped away just after dinner. \\
\hline & & 36-The sun melted the snow. \\
\hline & & 47-Poached eggs and tea must suffice. \\
\hline & \multirow[t]{3}{*}{ Adverbial Phrase } & 22-The next local elections will take place during the winter. \\
\hline & & 25-The young boy got up quite early in order to watch the sunrise. \\
\hline & & 32-Mother tied the string too tight. \\
\hline & Object & 1-He lost his white hat today. \\
\hline
\end{tabular}

Figure 3. Diversion in stress assignment (Arda-VP)

So far, it has been observed that Arda assigns the stress mostly on the subject and verb phrases while Simon has adopted other options. Table 7 displays the stress assignment diversions, in which 
Arda puts stress on phrases other than subject and verb. As can be seen, the stress is sometimes on the same word (see the instances 2 and 15), or within the same phrase (see the instances 45, 12, 24, 46) but assigned on a different syllable. However, there are also examples in the data set where Arda and Simon have made stress assignments far different than one another (see the instances 12, 9, 10, 18, 26, $21,34,38,49)$. This set has also some instances where Simon assigns the stress on the last syllable $(10,26,38)$ and Arda assigns the stress elsewhere.

Table 7. Diversion in stress assignment (other)

\begin{tabular}{|c|c|c|c|}
\hline \multirow{4}{*}{ NP } & \multirow{2}{*}{2} & A & Party game was really easy. \\
\hline & & $\mathrm{S}$ & Party game was really easy. \\
\hline & \multirow{2}{*}{45} & A & The candy shop is empty. \\
\hline & & $\mathrm{S}$ & The candy shop is empty. \\
\hline \multirow{2}{*}{ VP } & \multirow{2}{*}{15} & $\mathrm{~A}$ & This rugby season promises to be a very exciting one. \\
\hline & & $\mathrm{S}$ & This rugby season promises to be a very exciting one. \\
\hline \multirow{2}{*}{ AdjP } & \multirow{2}{*}{12} & $\mathrm{~A}$ & The art gallery in this street was open only last week. \\
\hline & & $\mathrm{S}$ & The art gallery in this street was open only last week. \\
\hline \multirow{2}{*}{ NP-AdjP } & \multirow{2}{*}{9} & A & Finding a job is difficult in the present economic climate. \\
\hline & & $\mathrm{S}$ & Finding a job is difficult in the present economic climate. \\
\hline \multirow{2}{*}{ NP-AdvP } & \multirow{2}{*}{10} & $\mathrm{~A}$ & Local train left the train station, more than five minutes ago. \\
\hline & & $\mathrm{S}$ & Local train left the train station, more than five minutes ago. \\
\hline \multirow{8}{*}{ AdjP-NP } & \multirow{2}{*}{18} & $\mathrm{~A}$ & Much more money will be needed to make this project succeed. \\
\hline & & $\mathrm{S}$ & Much more money will be needed to make this project succeed. \\
\hline & \multirow{2}{*}{24} & A & The first flowers have bloomed through the exceptional warmth of March. \\
\hline & & $\mathrm{S}$ & The first flowers have bloomed through the exceptional warmth of March. \\
\hline & \multirow{2}{*}{26} & $\mathrm{~A}$ & The last concert given in the Opera was a tremendous success. \\
\hline & & $\mathrm{S}$ & The last concert given in the Opera was a tremendous success. \\
\hline & \multirow{2}{*}{46} & A & A white silk jacket goes with any shoe. \\
\hline & & $\mathrm{S}$ & A white silk jacket goes with any shoe. \\
\hline \multirow{2}{*}{ AdjP-VP } & \multirow{2}{*}{21} & A & In this case, the easiest solution seems to appeal to the high court. \\
\hline & & $\mathrm{S}$ & In this case, the easiest solution seems to appeal to the high court. \\
\hline \multirow{2}{*}{ AdjP-S } & \multirow{2}{*}{34} & $\mathrm{~A}$ & There was a bad train wreck. \\
\hline & & $\mathrm{S}$ & There was a bad train wreck. \\
\hline \multirow{2}{*}{ S-AdjP } & \multirow{2}{*}{38} & $\mathrm{~A}$ & Scissors are very sharp. \\
\hline & & $\mathrm{S}$ & Scissors are very sharp. \\
\hline \multirow{2}{*}{ AdvP-AdjP } & \multirow{2}{*}{49} & A & The marsh will freeze when cold enough. \\
\hline & & $\mathrm{S}$ & The marsh will freeze when cold enough. \\
\hline
\end{tabular}

\subsection{Pitch assignment}

The pitch assignment is unearthed via extracting intensity contour graphs of each utterance and comparing them one by one. The pitch movements are clustered following the categorization of Dalton and Seidlhofer (1994), covering the movements such as fall, rise-fall, fall-rise, and level as exemplified hereunder with samples from the data set:

- Fall, as observed in the utterance 17

- Rise-Fall, as observed in the utterance 18

- Fall-Rise, as observed in the utterance 14

- Level, as observed in the utterance 11

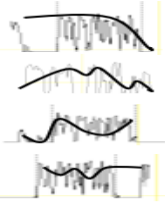

The data set has demonstrated similarities in 35 utterances out of 50, summarized in the Figure 4. The similarity in the pitch movement Level has mostly occurred in the data $(n=15)$. This can be explained with the prevalence of using the pitch movement Level in Turkish, which Arda is seemingly bringing alongside to his English utterances (see Figure 5). Following the prevalence of Level 
intonation, Rise-Fall $(\mathrm{n}=10)$ and Fall $(\mathrm{n}=10)$ are observed in the data set as having similar intonation regarding the utterances of Arda and Simon.

In this vein, the Fall intensity contour is mostly matched considering the utterances of Simon and Arda (See Figures 4 and 7). On the other hand, there are instances where Arda and Simon contrast with respect to their preferences of pitch movements as elaborated further in Figures 5, 6, and 7.

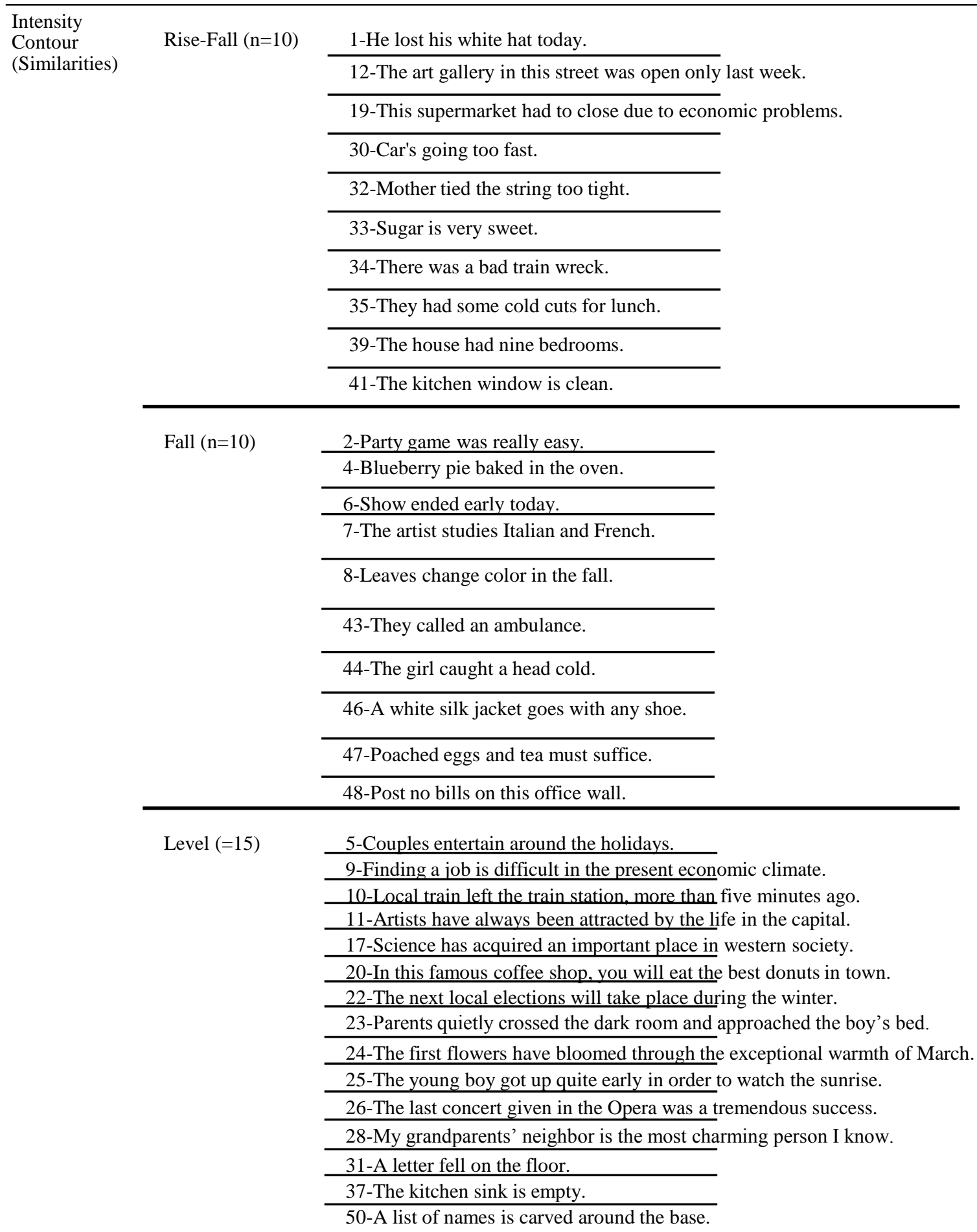

Figure 4. Pitch movements -similarities 
The stress assignment in the utterances affects the intonation patterns since the speakers place the stress in different syllables. In this regard, the utterance 14 (See Figure 5) is uttered with a falling intonation by Arda, since he already assigned the stress way earlier, unlike Simon. However, the case of the utterance 42 is rather segmental, since the word "letter" is pronounced as [letər], using schwa sound and finishing with almost an approximant by Simon; Arda pronounces it as [lettor], which both elongates the duration and changes the intonation overall.

\begin{tabular}{|c|c|c|}
\hline \multirow{7}{*}{$\begin{array}{l}\text { *Simon's } \\
\text { Intensity } \\
\text { Contour } \\
\text { is at } \\
\text { "Level" } \\
\text { for all } \\
\text { the } \\
\text { instances } \\
\text { displaye } \\
\text { d here. }\end{array}$} & Fall & $\begin{array}{l}\text { 14-The committee will meet this afternoon for a special debate. } \\
\text { 42-The mailman brought a letter. }\end{array}$ \\
\hline & Fall Rise & 18-Much more money will be needed to make this project succeed. \\
\hline & \multirow[t]{5}{*}{ Rise-Fall } & 15-This rugby season promises to be a very exciting one. \\
\hline & & 16-Nobody noticed when the children slipped away just after dinner. \\
\hline & & 21-In this case, the easiest solution seems to appeal to the high court. \\
\hline & & 27-The library is opened every day from 8 am to $6 \mathrm{pm}$. \\
\hline & & 29-Her shoes were very dirty. \\
\hline
\end{tabular}

Figure 5. Diversities in pitch movement (Arda-Level)

The effect of stress in creating a diversion in intonation can further be examined in Figure 6, where instances of such effect exist (see instances 3, 36, 38, and 40). Since the stress is assigned distinctively on the subject or the predicate, it changes the flow of pitch through the sentence.

\begin{tabular}{lll}
\hline *Simon's & Fall & 3-Twins live with their grandparents \\
\cline { 2 - 2 } $\begin{array}{l}\text { Intensity } \\
\text { Contour is at }\end{array}$ & Rise-Fall & 36-The sun melted the snow. \\
\cline { 2 - 2 } $\begin{array}{l}\text { for all the } \\
\text { instances } \\
\text { displayed } \\
\text { here. }\end{array}$ & & 38-Scissors are very sharp. \\
\cline { 2 - 2 }
\end{tabular}

Figure 6. Diversities in pitch movement (Arda-Fall Rise)

The use of Level pitch instead of Fall as examined in the utterance 45 and 49 (See Figure 7) might result in an expectation from the hearer about the unfolding of the event, which might lead to a communication breakdown on behalf of Arda as a non-native speaker. To index a finite clause, falling intonation is preferred by Simon.

\begin{tabular}{lll}
\hline *Simon's & Level & 45-The candy shop is empty. \\
\cline { 2 - 2 } $\begin{array}{l}\text { Intensity } \\
\text { Contour is at }\end{array}$ & & 49-The marsh will freeze when cold enough. \\
\cline { 2 - 2 } $\begin{array}{l}\text { "Fall" for all } \\
\text { the instances } \\
\text { displayed here. }\end{array}$ & Rise-Fall & 40-The man is painting a sign. \\
\cline { 2 - 2 } & &
\end{tabular}

Figure 7. Diversities in pitch movement (Arda-Fall) 


\subsection{Utilization of pause}

To identify the spots where Arda and Simon paused while uttering the sentences, the time intervals of pauses are extracted in milliseconds as displayed in Table 8. It is worth noting that not all utterances have a pause and the least amount that is recorded as a pause in this data set is four milliseconds $(0.04$ s). In this regard, 100 instances of pauses are analyzed and it is found out that only 38 of such pauses are recorded at a similar segmental environment, which is labeled as pairs in Table 8. Dividing the number of pairs by two, the number of occurrences can be found. That is, if there are sixteen pairs of utterances, they are actually eight in number.

It can be inferred that they tend to give a particular amount of time break after Subject $(n=34)$, Verb $(n=31)$, Adverb $(n=11)$, Adjective $(n=6)$, Determiner $(n=5)$, Object $(n=4)$, Sentence $(n=4)$, Noun Phrase ( $n=3)$, and Preposition $(n=2)$. Interestingly, there are no occurrences in Arda's utterances that are paired up with the pauses given after determiners and prepositions, unlike other words. There are also sample extracts for each such pairs under the columns labeled as Simon and Arda.

Table 8. Utilization of pause

\begin{tabular}{|l|l|l|l|}
\hline $\begin{array}{l}\text { The Word Preceding the } \\
\text { Pause }\end{array}$ & $\begin{array}{l}\text { Overall } \\
\text { Occurrence/ } \\
\text { Pairs }\end{array}$ & Simon & Arda \\
\hline Subject & $34 / 16$ & $\begin{array}{l}\text { The artist }(0.6) \text { studies Italian and } \\
\text { French. }\end{array}$ & $\begin{array}{l}\text { The artist (0.34) studies Italian and } \\
\text { French. }\end{array}$ \\
\hline Verb & $31 / 10$ & Show ended $(0.08)$ early today. & Show ended (0.17) early today. \\
\hline Adverb & $11 / 4$ & $\begin{array}{l}\text { A hurricane was announced this } \\
\text { afternoon }(0.27) \text { on the TV. }\end{array}$ & $\begin{array}{l}\text { A hurricane was announced this } \\
\text { afternoon }(0.24) \text { on the TV. }\end{array}$ \\
\hline Adjective & $6 / 2$ & $\begin{array}{l}\text { A white }(0.07) \text { silk jacket goes with } \\
\text { any shoe. }\end{array}$ & $\begin{array}{l}\text { A white silk }(0.16) \text { jacket goes } \\
\text { with any shoe. }\end{array}$ \\
\hline Determiner & $5 / 0$ & $\begin{array}{l}\text { Leaves change color in the }(0.11) \\
\text { fall. }\end{array}$ & No Occurrence \\
\hline Object & $4 / 2$ & $\begin{array}{l}\text { Mother tied the string }(0.05) \text { too } \\
\text { tight. }\end{array}$ & $\begin{array}{l}\text { Mother tied the string (0.13) too } \\
\text { tight. }\end{array}$ \\
\hline Sentence & $4 / 2$ & $\begin{array}{l}\text { Nobody noticed }(0.63) \text { when the } \\
\text { children slipped away just after } \\
\text { dinner. }\end{array}$ & $\begin{array}{l}\text { Nobody noticed }(0.05) \text { when the } \\
\text { children slipped away just after } \\
\text { dinner. }\end{array}$ \\
\hline Noun Phrase & $\begin{array}{l}\text { The last concert }(0.11) \text { given in the } \\
\text { Opera was a tremendous success. }\end{array}$ & $\begin{array}{l}\text { The last concert }(0.13) \text { given in the } \\
\text { Opera was a tremendous success. }\end{array}$ \\
\hline Preposition & $\begin{array}{l}\text { A white silk jacket goes with (0.15) } \\
\text { any shoe. }\end{array}$ & No Occurrence \\
\hline
\end{tabular}

To have a closer look at such pairs, the time intervals of pauses are compared with regards to the pauses Simon and Arda delivered just after Subjects (see Figure 8). Some instances of pauses are delivered with very similar amounts as in the utterances $19,26,43$, and 45 . On the other hand, there are also some pauses with different amounts as seen in the utterances 7, 14, 18, and 46. Simon seems to be assigning less amount of time for pauses except for the utterance 14. Longer pauses might interfere with speech perception (Kahng, 2018), thus causing a potential communication breakdown. 


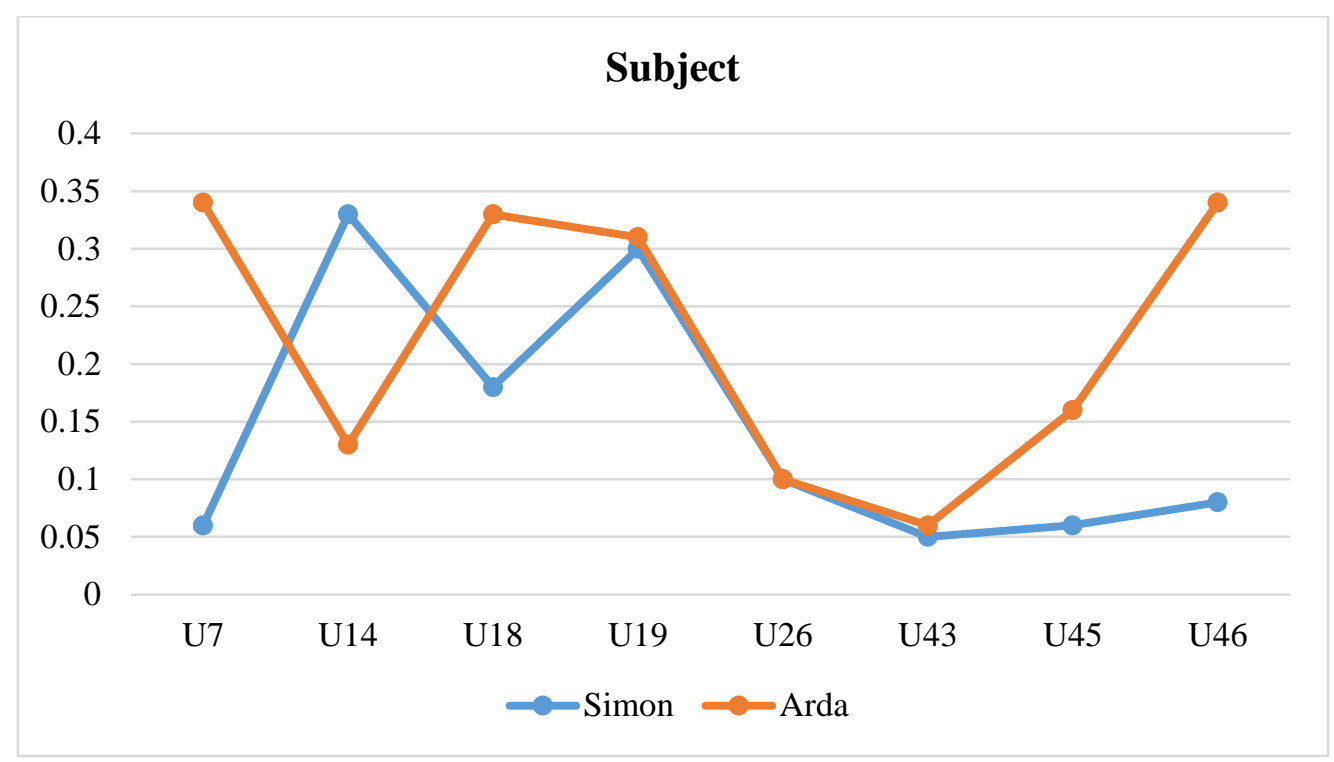

Figure 8. Paired comparison of pause (Subject)

In a similar vein, Figure 9 summarizes the pair of pauses that occurred after verbs. In line with Figure 9, Arda has usually a higher portion of pauses when compared to Simon in instances 6, 25, 40, and 41 . The only exception is observed in the utterance 24 with a slightly higher amount of pause delivered by Simon.

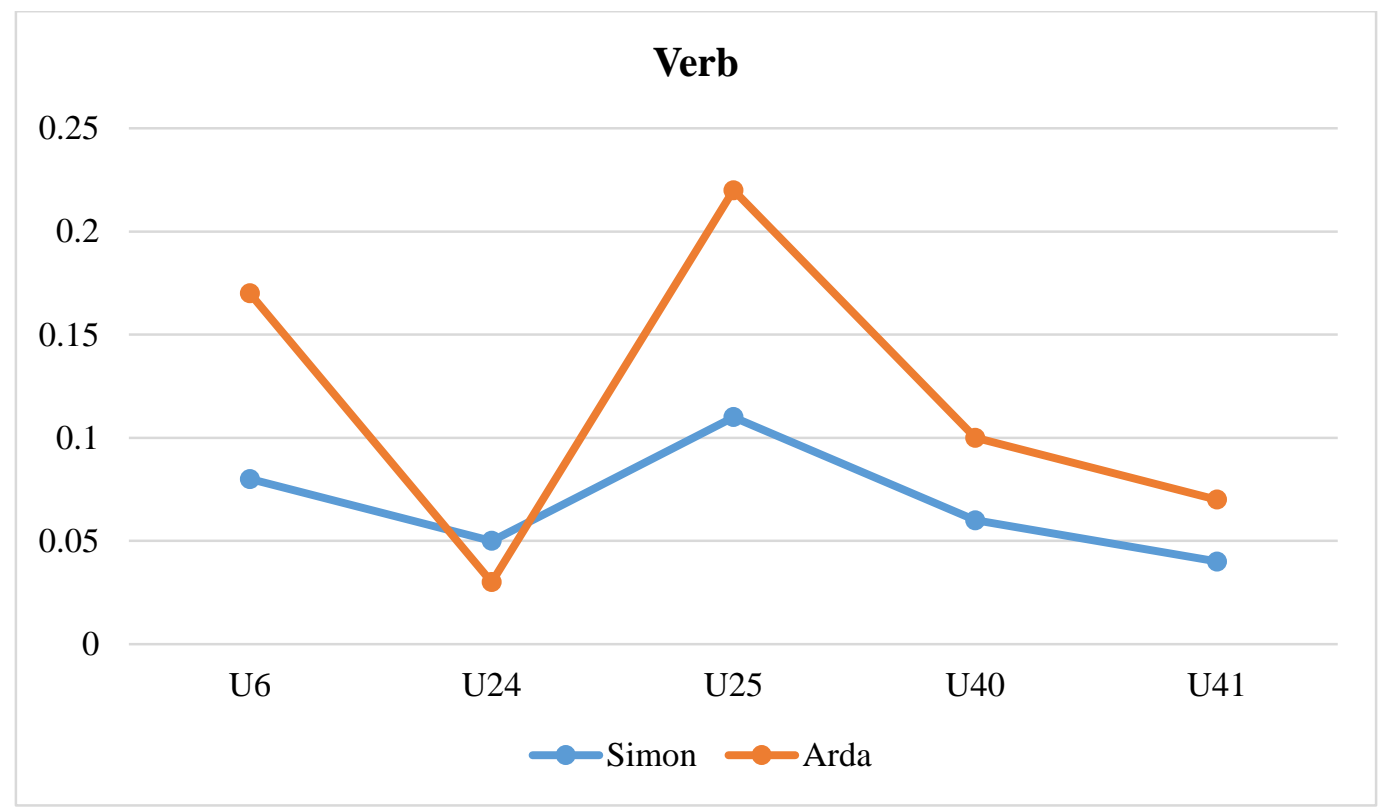

Figure 9. Paired comparison of pause (Verb)

Other examples that show alignment in the utilization of pause delivered by Arda and Simon can be observed in Figure 10. In contrast with other samples, where Arda usually makes use of longer duration to pause, there are some samples of Simon having longer time for pause (see instances 13, 16, 20, and 46) than Arda, except from the utterance 26, which has almost the same amount of time for pause. 


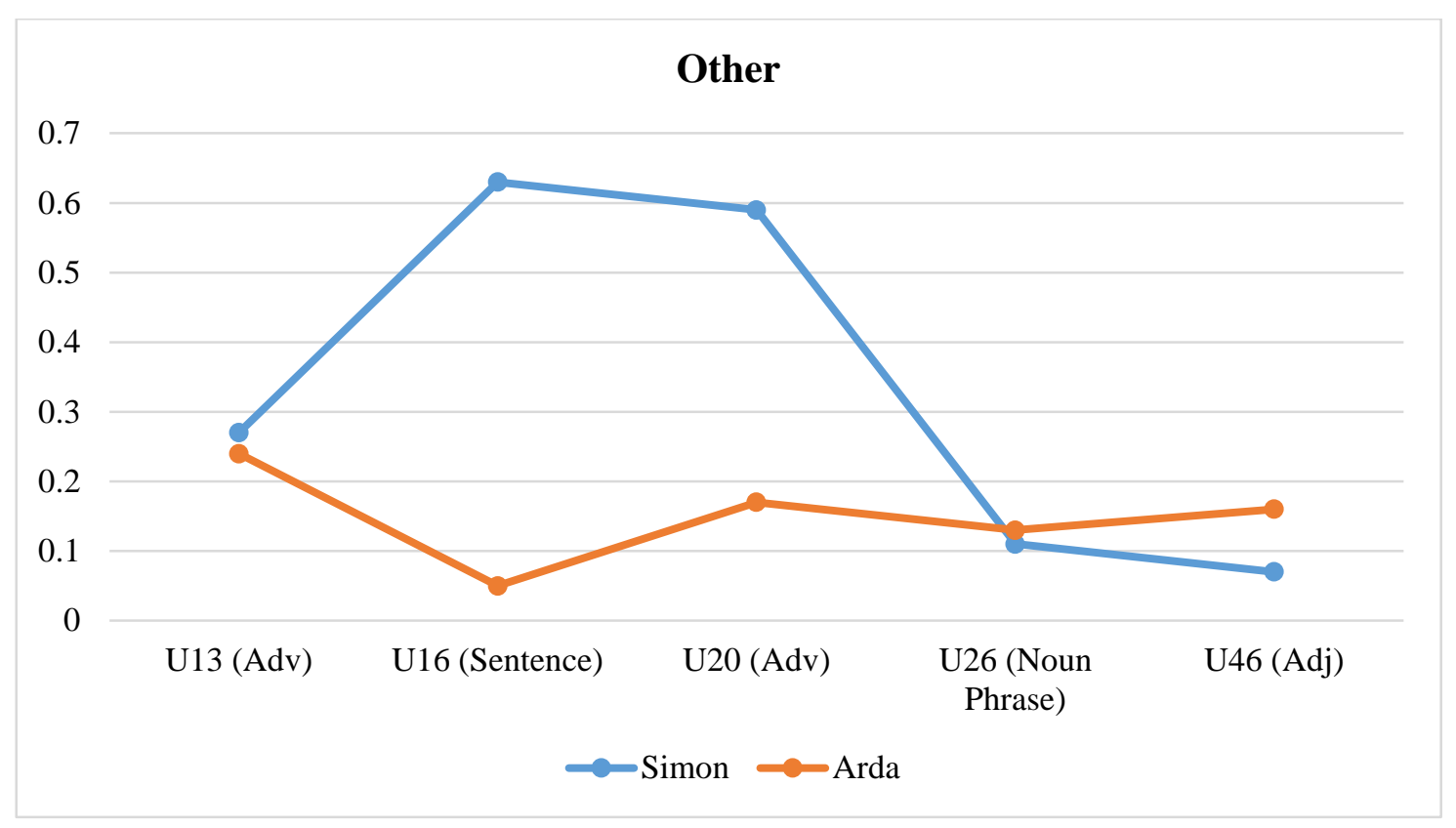

Figure 10. Paired comparison of pause (other)

\section{Discussion and Conclusion}

Throughout the years, pronunciation teaching has tended to overlook the teaching of suprasegmental elements and their crucial role in establishing intelligibility since the teaching of segmental features has outweighed. In this vein, it is argued that such a path might impede learners from noticing how those elements interact and change meaning overall (Pennington \& RogersonRevell, 2019). Building on such argument, some scholars suggest that stress patterns should be highlighted based on the comprehension of the interlocutors as they can be held responsible for particular diversions from the intelligibility (Chela-Flores, 2001; Fraser, 2001; Tanner \& Landon; 2009; Wang, 2020). With regards to the suprasegmental features and their role in intelligibility, there seems to be a low number of studies (Arslan, 2013; Çelik, 1999; Demirezen, 2009; Hişmanoğlu, 2012; Yurtbaş1, 2017) and dissertations (Kılınç \& Yıldırım, 2019; Kurt, 2018) conducted in Turkey. Therefore, the research on teaching and analyzing suprasegmental features is called for especially for Turkish preservice teachers of English (Arslan, 2013; Bardakci, 2015). Considering the potential fit for non-native learners' needs, this study has aimed at describing the similarities and diversions regarding suprasegmental features found in spoken data of a native and a non-native speaker. The data has arisen from the reading aloud task including fifty utterances. The analyses include inspections upon length, stress, pitch, and pause assignment undertaken by the speakers. Such analyses have made it possible to notice the differences, similarities, and some emerging recursive patterns.

As for the speech analyses, it has been examined that the speakers (Arda, non-native; Simon, native) assigned the length similar to a great extent $(n=28)$ by mostly uttering the last syllable the longest $(n=17)$. The diversion of length assignment $(n=22)$ is sometimes relevant to segmental features since Arda's addition of segment results in uttering a certain syllable longer than Simon. On the other hand, speech analyses on stress assignment have demonstrated that there are more diversions $(n=37)$ than similarities $(n=13)$. A closer look at the percentages of the duration of the stressed syllable compared to the whole utterance shows that Arda has typically assigned lower durations to the stressed syllables than Simon. The divergences of stress have implied that Arda tends to assign stress in the verb phrases or the subjects whereas Simon has variations. Sometimes, there are cases where they assign stress within the same phrase but on different syllables. Contrary to stress assignment, 
pitch assignment has similarities $(n=35)$ outnumbering diversions $(n=15)$. The speakers assign Level $(n=15)$, Fall $(n=10)$, and Rise-Fall $(n=10)$ type of pitch movements parallel to one another. However, it has been observed that suprasegmental and segmental features interact with one another, creating potential diversion points that surfaced in the speech. In this vein, some divergences could be predictable since they have been surfaced in the examination of stress, for instance. Finally, utilization of pause has revealed that only $28 \%$ of the pauses are similarly located but Arda usually spares more time for pause than Simon. The diversions on the pause assignment, on the other hand, show that Simon has a longer duration than Arda. In this regard, the longer duration for pauses than conventional use might impede the flow of communication (Kahng, 2018), causing potential breakdowns for mutual intelligibility.

There have been some practical suggestions upon how to incorporate suprasegmental features into pronunciation teaching in an EFL context. It has been argued that rather than entangled with prioritizing segmental or suprasegmental features, teachers or prospective teachers should be informed about how they operate and modify meaning in an utterance (Wang, 2020). In this way, Turkish EFL learners of English could be familiarized with the diversions of their use of suprasegmental features and trained towards excelling intelligibility. Through such training delivered in focused tasks, in which the learners pay attention to the sub-features of their pronunciation; they could integrate such improvements into the spontaneous speech over time (Chela-Flores, 2001). Furthermore, there are some online training websites (see Demirezen, 2009) and software such as PRAAT that might enhance the noticing of the interaction between segmental and suprasegmental features. In line with these types of aid; pairs of speech clips, which incorporate meaningful differences resulted from their divergences of suprasegmental features might also be utilized for raising awareness of the learners that such elements as length, stress, pitch, and pause can change the meaning.

Cracking the door that is barely knocked, the present study is not without limitations. There is only one non-native speaker of English; thus, the findings could be more comprehensive and representative if there were more Turkish learners of English at the same proficiency level. Moreover, there is a need for examining the potential reasons why such divergences occur. In this vein, the word stress and sentential stress can be examined exclusively to be able to scrutinize the stress patterns in isolated utterances and their readings in a sentence. By integrating more noticing activities, in which learners might develop their comprehension and production, the teachers might have an advantage over recovering unintelligible pronunciation practices of their learners.

\section{Acknowledgments}

I would like to thank Prof. Handan Yavuz for her valuable feedback and insights on this article.

\section{References}

Arslan, R. S. (2013). Enhancing non-native prospective English language teachers' competency in sentential stress patterns in English. Pamukkale University Journal of Education, 34(11), 183-195.

Avery, P. \& Ehrlich, S. (1992). Teaching American English pronunciation. Oxford, UK: Oxford University Press.

Bardakci, M. (2015). Turkish EFL pre-service teachers pronunciation problems. Educational Research and Reviews, 10(16), 2370-2378.

Bayraktaroğlu, S. (2008). Orthographic interference and the teaching of British pronunciation to Turkish learners. Journal of Language and Linguistic Studies, 4(2), 1-36. 
Bradlow, A. R. (n.d.) ALLSSTAR: Archive of L1 and L2 Scripted and Spontaneous Transcripts And Recordings. https://oscaar3.ling.northwestern.edu/ALLSSTARcentral/\#!/recordings.

Coates, C. (2020). The use of suprasegmentals in the production of emotion-affected speech between native English and native Korean speakers (Doctoral dissertation, University of Pittsburgh).

Celce-Murcia, M., Brinton, D. M., \& Goodwin, J. M. (1996). Teaching pronunciation: A reference for teachers of English to speakers of other languages. Cambridge University Press.

Celce-Murcia, M., Brinton, D. M., \& Goodwin, J. M. (2010). Teaching pronunciation hardback with audio CDs (2): A course book and reference guide. Cambridge University Press.

Chela-Flores, B. (2003). Optimizing the teaching of English suprasegmentals. Bells: Barcelona English language and literature studies.

Çelik, M. (1999). Learning stress and intonation in English. Ankara: Gazi Publishing.

Çelik, M. (2007). Linguistics for Students of English: Book 1. Ankara: EDM.

Dalton, C. \& Seidlhofer, B., Candlin, C. N. \& Widdowson, H. G. (Eds.). (1994). Pronunciation. Oxford: Oxford University Press.

Demirezen, M. (2009). An analysis of the problem-causing elements of intonation for Turkish teachers of English. Procedia-Social and Behavioral Sciences, 1(1), 2776-2781.

Derwing, T. M., Munro, M. J., \& Wiebe, G. (1998). Evidence in favor of a broad framework for pronunciation instruction. Language Learning, 48(3), 393-410.

Deterding, D. (1994). The intonation of Singapore English. Journal of the International Phonetic Association, 24(2), 61-72.

Devitska, A. I. (2019). English and Slovak language systems in contact: suprasegmental level.

Diaz, A. (2017). Towards Improving Japanese EFL Learners' Pronunciation: The Impact of Teaching Suprasegmentals on Intelligibility. APU Journal of Language Research, 69.

Djebbari, Z. (2014). Self Confidence and Pronunciation Training to Enhance the EFL Speaking Competence: A Classroom-oriented Research on First-Year LMD Students at Abu Bekr Belkaid University, Tlemcen (Doctoral dissertation).

Fraser, H. (2001). Teaching pronunciation: A handbook for teachers and trainers. Three frameworks for an integrated approach. Canberra: Department of Education, Training and Youth Affairs.

Ergenç, İ. (1989). Türkiye Türkçesiningörevselsesbilimi. Ankara: EnginYayınevi.

Evis, D. \& Kılıç, M. (2020). An Analysis of Lexical Stress in English Pronunciation of Indo-European Words Loaned to Turkish by Turkish Speakers of English. OPUS-International Journal of Society Researches, 10(15), 4739-4767.

Florez, M. C. (1998). Improving adult ESL learners' pronunciation skills. ERIC, National Clearinghouse for ESL Literacy Education.

Göksel, A., \& Kerslake, C. (2005). Third reprint 2010. Turkish, a comprehensive grammar.

Goodwin, J. (2013). Teaching pronunciation. In M. Celce-Murcia, D. M. Brinton \& M. A. Snow (Eds.), Teaching English as a second or foreign language (4th ed, pp. 136-152). Boston, MA: National Geographic Learning/Cengage Learning. 
Hişmanoğlu, M. (2012). An investigation of pronunciation learning strategies of advanced EFL learners. Hacettepe Üniversitesi Eğitim Fakültesi Dergisi, 43(43).

Hussain, S., \& Sajid, S. (2015). Applications of suprasegmental in EFL classroom: A short Review. International Journal of Scientific and Research Publications, 5(9), 1-7.

Kachru, B. B. (1992). World Englishes: Approaches, issues, and resources. Language teaching, 25(1), $1-14$.

Kahng, J. (2018). The effect of pause location on perceived fluency. Applied Psycholinguistics, 39(3), 569-591.

Kilinc, K., \& Yildirim, O. (2020). The Effects of Test Type, Pronunciation, and Proficiency Level on EFL Learners' Speaking Exam Scores. World Journal of Education, 10(3), 95-105.

Kurt, Ş. (2018). Raising EFL learners' awareness of suprasegmental features as an aid to understanding implicatures (Doctoral dissertation, Bilkent University).

Levis, J. M. (2005). Changing contexts and shifting paradigms in pronunciation teaching. Tesol Quarterly, 39(3), 369-377.

Lewis, G. (1967). Turkish grammar. London and New York: Oxford University Press.

Ma, R. (2015). The Role of Pronunciation in Speaking Test Ratings. Provo: Brigham Young University, Department of Linguistics and English Literature. MA Thesis.

Morley, J. (1991). The pronunciation component in teaching English to speakers of other languages. TESOL Quarterly, 25(3) 481-520. Retrieved from http://www.jstor.org/stable/3586981.

O'Connor, J. D. (1973). Phonetics. Harmondsworth, Middlesex: Penguin Books.

O'neal, G. (2010). The Effects of the Presence and Absence of Suprasegmentals on the Intelligibility and Assessment of an Expanding-Circle English Speaker according to other Expanding-Circle English Listeners. 新潟大学言語文化研究, 15, 65-87.

Pennington, M. C., \& Rogerson-Revell, P. (2019). English pronunciation teaching and research. Londres: Palgrave Macmillan., 10, 978-1.

Reed, M. \& Michaud, C. (2011). An Integrated Approach to Pronunciation: Listening Comprehension and Intelligibility in Theory and Practice. In. J. Levis \& K. LeVelle (Eds.). Proceedings of the 2nd Pronunciation in Second Language Learning and Teaching Conference, Sept. 2010. (pp. 95-104), Ames, IA: Iowa State University.

Scribd (2012). Stress words. Retrieved from http://www.scribd.com/doc/78735765/Stress-Words

Sirsa, H., \& Redford, M. A. (2013). The effects of native language on Indian English sounds and timing patterns. Journal of phonetics, 41(6), 393-406.

Smiljanic, R. \& Bradlow, A. R. (2005) Production and perception of clear speech in Croatian and English. Journal of the Acoustical Society of America, 118(3), 1677-1688.

Tanner, M., \& Landon, M. (2009). The effects of computer-assisted pronunciation readings on ESL learners' use of pausing, stress, intonation, and overall comprehensibility. Language Learning \& Technology, 13(3), 51-65.

Yurtbaş1, M. (2017). Correcting English learner's suprasegmental errors. Global Journal of Foreign Language Teaching, 7(4), 126-131. 
Wang, X. (2020). Segmental versus Suprasegmental: Which One is More Important to Teach? RELC Journal, 0033688220925926.

\section{Appendix A}

\section{A.1. The list of utterances for read-aloud}

U1- He lost his white hat today.

U2- Party game was really easy.

U3- Twins live with their grandparents.

U4- Blueberry pie baked in the oven.

U5- The couples entertain around the holidays.

U6- The show ended early today.

U7- The artist studies Italian and French.

U8- Leaves change color in the fall.

U9- Finding a job is difficult in the present economic conditions.

U10- Local train left the train station, more than five minutes ago.

U11- Artists have always been attracted to life in the capital.

U12- The art gallery in this street was open only last week.

U13- A hurricane was announced this afternoon on the TV.

U14- The committee will meet this afternoon for a special debate.

U15- This rugby season promises to be a very exciting one.

U16- Nobody noticed when the children slipped away just after dinner.

U17- Science has acquired an important place in western society.

U18- Much more money will be needed to make this project succeed.

U19- This supermarket had to close due to economic problems.

U20- In this famous coffee shop, you will eat the best donuts in town.

U21- In this case, the easiest solution seems to appeal to the high court.

U22- The next local elections will take place during the winter.

U23- Parents quietly crossed the darkroom and approached the boy's bed.

U24- The first flowers have bloomed through the exceptional warmth of March.

U25- The young boy got up quite early in order to watch the sunrise.

U26- The last concert given in the Opera was a tremendous success.

U27- The library is opened every day from 8 am to $6 \mathrm{pm}$.

U28- My grandparents' neighbor is the most charming person I know.

U29- Her shoes were very dirty.

U30- The cars are going too fast.

U31- A letter fell on the floor.

U32- Mother tied the string too tight.

U33- Sugar is very sweet.

U34- There was a bad train wreck.

U35- They had some cold cuts for lunch.

U36- The sun melted the snow.

U37- The kitchen sink is empty.

U38- Scissors are very sharp.

U39- The house had nine bedrooms.

U40- The man is painting a sign.

U41- The kitchen window is clean.

U42- The mailman brought a letter.

U43- They called an ambulance.

U44- The girl caught a head cold.

U45- The candy shop is empty.

U46- A white silk jacket goes with any shoe.

U47- Poached eggs and tea must suffice.

U48- Post no bills on this office wall.

U49- The marsh will freeze when cold enough.

U50- A list of names is carved around the base. 


\section{Appendix B}

\begin{tabular}{|c|c|}
\hline Similarity in Stress Assignment & Diversion in Stress Assignment \\
\hline Blueberry pie baked in the oven. & He lost his white hat today. \\
\hline Couples entertain around the holidays. & Party game was really easy. \\
\hline Leaves change color in the fall. & Twins live with their grandparents. \\
\hline This supermarket had to close due to economic problems. & Show ended early today. \\
\hline $\begin{array}{l}\text { In this famous coffee shop, you will eat the best donuts in } \\
\text { town. }\end{array}$ & The artist studies Italian and French. \\
\hline Her shoes were very dirty. & Finding a job is difficult in the present economic climate. \\
\hline Car's going too fast. & Local train left the train station, more than five minutes ago. \\
\hline A letter fell on the floor. & Artists have always been attracted by life in the capital. \\
\hline Sugar is very sweet. & The art gallery in this street was open only last week. \\
\hline The kitchen sink is empty. & A hurricane was announced this afternoon on the TV. \\
\hline The kitchen window is clean. & The committee will meet this afternoon for a special debate. \\
\hline The mailman brought a letter. & This rugby season promises to be a very exciting one. \\
\hline They called an ambulance. & $\begin{array}{l}\text { Nobody noticed when the children slipped away just after } \\
\text { dinner. }\end{array}$ \\
\hline \multirow[t]{23}{*}{ Post no bills on this office wall. } & Science has acquired an important place in western society. \\
\hline & $\begin{array}{l}\text { Much more money will be needed to make this project } \\
\text { succeed. }\end{array}$ \\
\hline & $\begin{array}{l}\text { In this case, the easiest solution seems to appeal to the high } \\
\text { court. }\end{array}$ \\
\hline & The next local elections will take place during the winter. \\
\hline & $\begin{array}{l}\text { Parents quietly crossed the darkroom and approached the } \\
\text { boy's bed. }\end{array}$ \\
\hline & $\begin{array}{l}\text { The first flowers have bloomed through the exceptional } \\
\text { warmth of March. }\end{array}$ \\
\hline & $\begin{array}{l}\text { The young boy got up quite early in order to watch the } \\
\text { sunrise. }\end{array}$ \\
\hline & $\begin{array}{l}\text { The last concert given in the Opera was a tremendous } \\
\text { success. }\end{array}$ \\
\hline & The library is opened every day from 8 am to $6 \mathrm{pm}$. \\
\hline & $\begin{array}{l}\text { My grandparents' neighbor is the most charming person I } \\
\text { know. }\end{array}$ \\
\hline & Mother tied the string too tight. \\
\hline & There was a bad train wreck. \\
\hline & They had some cold cuts for lunch. \\
\hline & The sun melted the snow. \\
\hline & Scissors are very sharp. \\
\hline & The house had nine bedrooms. \\
\hline & The man is painting a sign. \\
\hline & The girl caught a head cold. \\
\hline & The candy shop is empty. \\
\hline & A white silk jacket goes with any shoe. \\
\hline & Poached eggs and tea must suffice. \\
\hline & The marsh will freeze when cold enough. \\
\hline & A list of names is carved around the base. \\
\hline
\end{tabular}

\section{AUTHOR BIODATA}

Nur Sürüç Şen is a Ph.D. student at Anadolu University under the program of English Language Teaching. She holds a BA degree in the Foreign Language Education program at Bogazici University. Her research interests include pre-service and in-service teacher education along with some other topics covered in sociolinguistics and applied linguistics. 